\title{
CULTURA DOS ALUNOS NA PRÉ-ESCOLA E NA “ESCOLA PRIMÁRIA"
}

\author{
Ruth Bernardes de Sant'Ana \\ Universidade Federal de São João del-Rei (UFSJ)
}

RESUMO: O objetivo deste artigo é discutir a cultura dos alunos, com ênfase na pré-escola e nos primeiros anos do Ensino Fundamental ("escola primária"). As escassas teorizações sobre o assunto mostram limitações, na medida em que recaem sobre os alunos das últimas séries do Ensino Fundamental ou sobre o Ensino Médio, ou seja, sobre os adolescentes como grupo etário. A partir de dados de pesquisa de campo e de estudos teóricos, identificamos que a cultura dos alunos é uma cultura intraescolar, que se concretiza na intersecção entre a cultura infantil e a cultura escolar, com diferentes níveis de proximidade e distanciamento entre elas. Ela envolve comportamentos estratégicos infantis de oposição e de resistência às tarefas e ao poder docente. Quando a escola recusa o acolhimento da cultura infantil, esta se produz nos interstícios das atividades escolares, por vezes de maneira conflituosa.

Palavras-chave: Criança. Pré-Escola. Ensino Fundamental. Cultura. Alunos.

http://dx.doi.org/10.1590/0102-4698134606

* Pós-doutora pelo Instituto de Estudos da Criança (IEC) da Universidade do Minho, Portugal. Professora do Programa de Mestrado em Educação da Universidade Federal de São João del-Rei (UFSJ). Membro do Laboratório de Pesquisa e Intervenção Psicossocial (LAPIP/UFSJ). E-mail: ruthbs.ufsj@gmail.com 


\section{PUPIL'S CULTURE IN PRESCHOOL AND PRIMARY SCHOOL}

ABSTRACT: The goal of this paper is to undertake a study about student's culture, with an emphasis on pre-school and early years of elementary school (also called "primary school"). The few theories on the subject show limitations, in the sense that they verse about the students attending the last grades of elementary school or the high school - that is, adolescents as age group. Through data from field research and theoretical studies, we identified that student's culture is an intra-school one, which is developed at the intersection between child culture and school culture, with different levels of closeness and distance between them. It involves children's strategic behavior based on opposition and resistance to the tasks and the teacher's authority. When the school refuses to receive child culture, the latter occurs in the interstices of school activities, sometimes in a controversial manner.

Keywords: Child. Preschool. Primary education. Culture. Pupils.

\section{INTRODUCุ̃̃O}

O objetivo deste artigo consiste em discutir acerca da cultura dos alunos, com ênfase na pré-escola e nos primeiros anos do Ensino Fundamental ("escola primária"1). As teorizações sobre o assunto mostram limitações, na medida em que recaem sobre os alunos das ultimas séries do Ensino Fundamental ou sobre os do Ensino Médio, ou seja, sobre os adolescentes como grupo etário.

A reflexão recorre a Waller (1932), autor pioneiro na discussão acerca do aluno e de sua cultura como ponto de partida do debate acerca do assunto e referência para a reflexão sobre a resistência dos alunos à organização escolar, bem como a Perrenoud (1988), na sua teorização sobre as estratégias dos alunos da escola primária em face das tarefas escolares. A título de exemplificação da resistência discente, o artigo recorre a pesquisas desenvolvidas por Sant'Ana (2010, 2007) na pré-escola e na primeira série do Ensino Fundamental, no município de São João del-Rei, Minas Gerais.

Consideramos que a experiência escolar das novas gerações, da pré-escola à universidade, é construída a partir da relação entre os referenciais socioculturais infantis e juvenis e a cultura escolar, como estabelecida em cada etapa da escolarização; no "aqui e agora" da interação no cotidiano escolar. A partir de Waller (1932), podemos esboçar uma compreensão sobre a cultura dos alunos como localizada em algum ponto de intersecção entre a cultura na escola e a cultura escolar, conforme o contexto escolar, o tipo de ensino e a classe de idade dos alunos e as dinâmicas de interação social dos alunos entre si e com os professores. 
Embora essa cultura possa apresentar diferentes configurações, o que as unifica é a necessidade cotidiana de lidar com o poder docente e as atividades escolares. A cultura dos alunos inclui movimentos infantojuvenis de subordinação e autonomia, de concordância e discordância, de resistência e adesão ao currículo formal, que é imposto aos alunos sob a forma de tarefas.

Dubet e Martuccelli (1986) compreendem o mundo do aluno da "escola primária" francesa como dominado por um conformismo no interior do grupo de pares, visto que a experiência infantil é considerada pelos autores como marcada por um movimento acentuado de integração às exigências escolares. Entretanto, ao mesmo tempo em que existem, no interior da classe, uma sensibilidade e uma cultura infantis, elas não são ainda legítimas "face aos critérios escolares, elas se desenvolvem na sombra da escola" (DUBET; MARTUCELLI, 1986, p. 73). Alguma tensão entre as crianças e os alunos que habitam esses sujeitos só é perceptível em alunos entre 9 e 11 anos, segundo os autores, que explicam tal especificidade pela teoria do desenvolvimento de Piaget.

A reflexão dos autores nos indica que uma cultura infantil ou juvenil pode fazer parte da cultura escolar se adquirir legitimidade "face aos critérios escolares", ou seja, ganhar algum reconhecimento no desenvolvimento das atividades que compõem a rotina escolar, entrando de alguma forma no domínio "curricular". Isso pode ser deslocado para outro sentido, em termos de desvio e de oposição "face aos critérios escolares", pela recusa, aberta ou não, das tarefas e/ou das relações de poder que as acompanham.

A partir da afirmação de Dubet e Martuccelli (1986), podemos supor que, no caso por eles investigado, existe uma cultura de alunos, com formas de sociabilidade propriamente infantis, compartilhada por crianças no interior da "escola primária", mas que não se confronta com a cultura escolar e o poder docente. Ela constitui um mundo de cultura e sociabilidade infantis paralelo às atividades escolares e que permanece como um enclave no interior da escola.

Esse tipo de postura assumida por Dubet e Martuccelli (1986) diante da escolarização da infância desautoriza que falemos em oposição ou resistência infantil à escola e ao poder docente. A cultura dos alunos como cultura de oposição seria uma prerrogativa dos adolescentes ou de pré-adolescentes, pois, na infância, a cultura infantil na escola encontraria-se "em continuidade e identificação com a cultura do professor” (DUBET; MARTUCCELLI, 1986, p. 73).

Woods (1980) apela ao conceito interacionista de "carreira" para discutir o percurso escolar do aluno, alegando que "há apropriadas estratégias para cada ponto ao longo dessas carreiras, 
influenciadas por fatores como status, poder e aspirações, e também diferentes estratégias entre diferentes carreiras" (WOODS, 1980, p. 17). Do ponto de vista de Woods (1980), no transcorrer do seu itinerário escolar, o aluno aprende a perspectivar a sua ação, a "jogar o jogo". À medida que ele avança no processo de escolarização, mais competência para o jogo estratégico ele pode obter. Assim, é mais provável que adolescentes sejam mais experientes do que crianças na competência de "negociar" com os educadores um tempo para a expressão de suas sociabilidades dentro e fora da sala de aula.

Para o autor, toda vida na escola é desse tipo, pois mesmo o aluno mais conformista não necessariamente se adéqua aos ideais do professor, em um jogo de distanciamento crítico em relação às concordâncias e aos compromissos que ajudam a atingir seus alvos, considerando-se os alvos e os recursos alternativos. Por isso, Woods (1980) estabelece "uma tipologia da negociação pelo aluno" a respeito do investimento, por um lado, no "trabalho duro" extremo, "implicando completo compromisso e próximo da completa identificação com os alvos do professor", e, por outro, na "evitação do trabalho escolar, implicando total falta de compromisso e rejeição de qualquer negociação de base" (WOODS, 1980, p. 14).

De fato, as crianças pequenas também negociam, porém não necessariamente com a mesma gramática relacional dos adolescentes, podendo ganhar algum poder estratégico sem a consciência clara de como isso se dá efetivamente. Geralmente, as crianças pequenas querem liberdade para brincar e não aceitam facilmente estar em meio a grupos de pares ${ }^{2}$ e não poder viver a ludicidade. Em situações em que pouco tempo é dedicado a jogos e brincadeiras, as crianças, por mais identificadas que estejam com os objetivos de seus professores, não concordam que a escola seja um espaço disciplinar no qual o lúdico deva ser realmente interdito. Elas podem calar-se sem, no entanto, aderir completamente à definição da situação dada pelos professores; porém, entre outras coisas, uma menor experiência pode levá-las a ceder mais facilmente ao controle da situação pelo professor.

\section{ESCOLA MODERNA E CULTURA DOS ALUNOS}

A escola moderna se instituiu em meio à constituição de relações sociais baseadas na impessoalidade das normas de conduta de alunos e professores. No âmbito mais específico da escola, deu-se o disciplinamento das relações pedagógicas pela expulsão dos aspectos espontâneos de um estilo de vida mais livre e, consequentemente, 
a transformação de uma relação comunitária entre mestres e alunos, em uma relação de governo dos segundos pelos primeiros (VINCENT, LAHIRE \& THIN, 2001). Essa forma escolar, concebida como a configuração assumida pela instituição destinada à instrução de diferentes segmentos sociais e em diferentes contextos, permite integrar as escolas em sistemas escolares unificados em torno de uma matriz comum, ou seja, a separação dos educandos em relação aos professores por critérios etários, o escalonamento da progressão dos alunos no tempo, a organização didática e assim por diante.

A instituição de um padrão hierárquico de relação decorrente da distinção e da delimitação geracionais contribuiu, sobretudo a partir de meados do século XX, para o incremento dos processos identitários dos mais jovens, pois, "como os menores foram adquirindo sua identidade autônoma nas relações com os adultos, ambos se dividiram em dois mundos sociais" (SACRISTÁN, 2005, p.51). As crianças e os adolescentes consolidaram seu mundo paralelo principalmente na escola, apesar de serem considerados, do ponto de vista da organização lógica do pensamento e da ação, como adultos diminuídos. Os adultos agem como se estivessem numa posição superior e se sentem responsáveis por ensinar os mais novos (SACRISTÁN, 2005).

Assim, a idade passou a ser um critério organizador da vida coletiva que marca a dependência dos menores em relação aos adultos. O mundo dos "menores" é construído em referência e oposição ao mundo dos adultos. Isso significa assumir que a escola, como instituição caracterizada por relações hierárquicas e jogos interacionais constituídos historicamente, acabou por configurar um conjunto de padrões de comportamento envolto em um jogo de dominação e subordinação geracional que, entre outras coisas, acabou por constituir a cultura dos alunos. Essa cultura envolveria demarcações de fronteiras geracionais com maior ou menor flexibilidade e maior ou menor embate entre as partes que transitam inter- e intrafronteiras, conforme o contexto sociocultural. Embora não se trate de uma cultura homogênea, o processo histórico de constituição da relação professor-aluno como uma relação hierárquica em termos de poder e saber seria o elemento distintivo da cultura dos alunos em relação à cultura escolar, na medida em que esta fornece uma firme plataforma para a ação (WOODS, 1980). Assim, a cultura dos alunos oferece referências para a ação individual ou grupal em relação à cultura escolar, ao dispor para crianças e adolescentes uma gama de comportamentos aos quais eles podem recorrer para lidar com a configuração cultural da escola, em termos de aceitação ou oposição ao projeto educativo docente. 
A forma dominante de organização da escola moderna, ao assumir como sua a missão de educar as novas gerações por meio de uma posição "adultocêntrica", passou a exigir da criança atividade mental silenciosa e passividade corporal (SACRISTÁN, 2005). Desse modo, qualquer criança que, durante as aulas, ousasse realizar uma atividade diferente da lição, tal como a ocorrência de interação social paralela, era repreendida ou punida (VASQUEZ-BRONFMAN; MARTINEZ, 1996). Essa representação da escola, com alguma exceção para o "jardim de infância", levou à supervalorização da interação professor-aluno em detrimento da interação criança-criança. Hoje, ao menos teoricamente, a interação entre os pares também é concebida como uma experiência de socialização fundamental. Ela é considerada como capaz de pôr em ação uma cultura da infância, que, em determinados contextos, entra em conflito, em maior ou menor grau, com a forma escolar.

Para Waller (1932), o conflito é algo constitutivo da escola como instituição com atribuições sociais específicas no interior da sociedade. $\mathrm{O}$ autor compreende que a escola tem uma cultura que se diferencia da de outras instituições sociais, tendo em vista seus valores e seu sistema simbólico. Desse modo, embora haja diferenças entre as escolas, todas têm em comum uma relação de dominação e subordinação geracional específica que opera na distinção escola/não escola. Segundo o autor, toda e qualquer escola, mesmo aquelas que professam os valores pedagógicos mais democráticos, deve se haver com a questão da dominação geracional que subjaz a toda e qualquer relação pedagógica. Por isso, o autor reflete sobre a dificuldade posta para o exercício da atividade docente em uma relação que exige sempre essa assimetria adulto/criança ao dizer:

Penso que uma pedagogia esclarecida pode melhorar o conflito de adultos e crianças, mas ela nunca pode removê-lo por completo. Na escola mais humana alguma tensão aparece entre professor e alunos, o que resulta aparentemente, do papel que a condição impõe sobre o professor em relação aos seus alunos [...]. As atividades podem reduzir os conflitos mas não destruí-los (WALLER, 1932, p. 107).

Assim sendo, para o autor, mesmo a melhor pedagogia não pode eliminar a permanente tensão subjacente à educação escolar, cujo mandato social é de instrução das novas gerações. Autores contemporâneos como Bernstein (1996) e Perrenoud (1988) muito auxiliam a compreensão dessa relação, ao mostrarem que mesmo as pedagogias que se opõem à escola tradicional, constituindo "pedagogias ativas", envolvem formas de controle docente e formas de resistência a esse controle, o que retomaremos adiante. Por isso, na escola, o professor e o aluno enfrentam um conflito de interesses, 
e, por mais que ele possa ser escamoteado, escondido, esse conflito permanece, porque a escola está organizada no princípio da autoridade e essa autoridade está constantemente ameaçada pela coexistência, no espaço escolar, de duas lógicas conflitantes, uma voltada ao trabalho e outra voltada à sociabilidade, ou seja, à "vida espontânea"; ao "mundo próprio" dos alunos.

\section{CULTURA NA ESCOLA E CULTURA ESCOLAR}

Conforme Waller (1932), a escola é um local de encontro de diferentes culturas, mas ele prefere ater-se à cultura do professor e à dos alunos. Quando reflete acerca desta última, o autor, em muitos momentos, parece referir-se à cultura da infância. Assim,

\footnotetext{
Podemos ilustrar bem essa mistura de culturas se dividimos a tradição dos grupos na escola em três classes: a tradição que vem inteiramente, ou quase inteiramente, do lado de fora; a tradição que é em parte exterior à escola; e a tradição que é quase inteiramente indígena. Grosso modo, é verdade que a tradição da primeira classe existe na comunidade em geral, que a de segunda classe entre professores, e a da terceira classe entre os estudantes (WALLER, 1932, p. 108).
}

O autor concebe as crianças como produtoras de uma cultura própria por meio de uma apropriação muito particular da tradição cultural. Ele trata a cultura da infância como aborígene, pois as crianças fazem uma apropriação muito renovada do que dizem e fazem os adultos. Mesmo que parte da cultura das crianças seja originária de atividades desenvolvidas por professores, as crianças se apropriam delas conforme seus próprios modos. Ela é fruto, portanto, de uma socialização entre pares referenciada em experiências intra- e intergeracionais. Waller (1932, p.23) considera que

\footnotetext{
uma distinta cultura, nós dissemos, foi desenvolvida na escola. É uma cultura que é em parte a criação de crianças de idades diferentes, a partir do desmembramento da cultura adulta em configurações simples ou a sobrevivência de uma cultura antiga de jogos grupais infantis, e em parte desenvolvida por professores para canalizar as atividades das crianças que atravessam certas idades. [...] "Atividades", que muitos jovens consideram, de longe, a parte mais importante da vida escolar, são modelos de cultura. A cultura juvenil é muito real e satisfatória para aqueles que vivem dentro dela [...].
}

Portanto, o autor nomeia como tradição indígena a cultura infantil porque ela é, pelo menos em parte, fruto de uma aprendizagem impensada pelos adultos. A partir de Waller (1932), podemos afirmar que ela é originaria de uma socialização assistemática que segue, sobretudo, formas de transmissão oral. $\mathrm{Na}$ sua reflexão, o autor confere relevo ao processo de transmissão cultural ao sustentar que 
a tradição indígena da escola encontra-se em sua forma mais pura entre os estudantes. Esta tradição, quando tiver sido originada no local, é passada, em grande parte de boca em boca, de um aluno para outro [...]. Algumas das observâncias tradicionais que os alunos seguem não foram desenvolvidas em casa; há uma grande literatura da vida escolar, e, ocasionalmente, os alunos aparecem estar fazendo o papel de heróis de histórias de livros. Além disso, existe na cultura de qualquer comunidade um conjunto de atitudes tradicionais em relação à escola e à vida escolar, variando de uma classe social para outra, e de família para família; estas atitudes influenciam profundamente as atitudes que os alunos têm em relação à vida escolar. No entanto, a tradição dos alunos é, em grande parte indígena dentro da escola em particular. Embora este tipo de tradição varie muito em detalhe de uma escola para outra, podemos citar algumas características dos padrões fundamentais (WALLER, 1932, p. 109-110).

Desse modo, podemos conceber a cultura dos alunos como uma cultura intraescolar, mas que só em parte pode ser considerada uma cultura da escola, pois é originária de fora ou de dentro da escola, mas é transmitida no interior dos grupos de estudantes. A cultura dos alunos segue referências instituídas historicamente, mas que são restabelecidas e renovadas dentro de cada estabelecimento em particular e se manifesta, sobretudo, nos interstícios das atividades ligadas às funções sociais delegadas à escola.

Para avançar essa discussão, o presente estudo volta-se para as expressões da cultura dos alunos, crianças e adolescentes, da préescola e do Ensino Fundamental, na busca de uma compreensão mais ampla do tema. Especificamente, a discussão está orientada pelos seguintes questionamentos: 1) Como se apresenta na escola, sobretudo na sala de aula, a cultura dos alunos? 2) Como ela se expressa na pré-escola e nos primeiros anos do ensino fundamental do ponto de vista do exercício do "oficio do aluno"?

\section{A CRIANÇA-ALUNO NA PRÉ-ESCOLA}

A sociologia da infância (ver SIROTA, 2001; MONTANDON, 2001; SARMENTO, 2000, 2005) tem promovido enormes avanços na discussão sobre a relação entre as instituições de formação e a infância, com destaque para a escola contemporânea como lugar em que se concretiza um dos "ofícios da criança" (CHAMBOREDON; PREVOT, 1986), ou seja, o "ofício de aluno" (PERRENOUD, 1988). No interior desse movimento, Sarmento (2000) reconhece nas escolas espaços para circulação de culturas infantis, que nascem e se nutrem da interação entre pares, um mundo informal da sociabilidade (e da socialização) infantil paralelo ao mundo formalizado da escola, pois, 


\begin{abstract}
ao entrarem na escola, as crianças estabelecem entre si relações de cooperação e de competição que aproveitam dos contextos informais da escola para continuamente se actualizarem: os recreios, os intervalos, os momentos de descontracções no interior das salas de aula constituem espaços e momentos que favorecem a construção dessas interacções e contribuem para a sua padronização. Nesses espaços e momentos as crianças celebram os protocolos das suas interacções, criando grupos de afinidades e de exclusão, ao mesmo tempo que constroem perspectivas sobre si próprios como grupo. (SARMENTO, 2000, p. 398)
\end{abstract}

A cultura dos alunos da pré-escola pode ser concebida dessa forma? Ou seja, como um mundo informal da sociabilidade infantil que ocorre apenas nos interstícios do mundo formalizado da escola? Esse fenômeno é independente do curriculum escolar? Noutros termos, em nenhum modelo de práticas pedagógicas a cultura da infância ou, mais precisamente, parte dessa cultura pode fazer parte da cultura escolar?

Consideramos que o curriculum escolar guarda uma enorme relação com o lugar ocupado pela cultura da infância na educação infantil. Então, devemos levar em consideração o projeto formativo da escola em questão, em termos de didáticas que têm a criança como centro ou, mais comumente, que são centradas no professor. Quanto mais a prática pedagógica se aproxima da escola tradicional, mais ela se distancia da cultura da criança e do adolescente e vice-versa.

A pré-escola constitui a modalidade de educação escolar mais preocupada com a cultura da infância. Pelo menos do ponto de vista formal, no seu curriculum aparece como essencial o jogo infantil coletivo, compreendido como uma das formas específicas de interação infantil. No processo histórico de constituição da pré-escola incorporaram-se jogos e brincadeiras disponíveis socialmente, bem como foram criados novos dispositivos lúdicos infantis. A ideia de sociabilidade (a forma lúdica da socialização) tem um lugar dominante na representação da pré-escola e, ao menos teoricamente, opõe-se a um dualismo da vida social que separa as interações lúdicas, próprias da sociabilidade, e as interações sérias, relacionadas a conteúdos mais propriamente pedagógicos, ou seja, as tarefas escolares.

Se a cultura da infância é, sobretudo, uma cultura da sociabilidade infantil, o curriculum da pré-escola poderia ser visto como incorporando parte da cultura da infância no seu interior. Assim, ele seria exemplar para mostrar que pode existir uma cultura de alunos que não é estranha ao projeto educativo da escola e que, portanto, não se localiza nos interstícios das atividades sérias promovidas pela instituição. Nessa perspectiva, a cultura da infância na escola também pode fazer parte da cultura escolar. Assim, podemos falar de uma 
cultura infantil presente na rotina escolar, ou seja, na organização temporal das atividades, com sua linguagem, seus ritmos e ritos, seus modos próprios de produção e de gestão de símbolos. Noutros termos, na pré-escola a cultura infantil poderia ocupar um lugar bem importante no interior do trabalho pedagógico, configurando uma cultura na escola e da escola. Não se trataria, então, de transformar uma criança em aluno, mas de recusar a visão clássica que se tem do aluno em nome das conquistas da infância, ou seja, do direito a brincar.

Porém, uma pesquisa desenvolvida por Sant'Ana $(2002,2010)$ em uma instituição pré-escolar que pode ser caracterizada como "tradicional" mostra que, ali, a criança deve aprender a ser aluno, a conviver com uma rotina repetitiva; com uma didática tradicionalista que compreende tarefas parcelares, como preenchimento de folhas mimeografadas; com atividades mecânicas de memorização; com práticas como colorir desenhos feitos pela professora, etc. O que caracteriza a pedagogia da escola estudada é o modelo centrado no professor, e não na criança, na maior parte das atividades. Por isso, jogos e brincadeiras ocorrem, mas em menor quantidade em relação às atividades de leitura e escrita. Ao desenvolver uma rotina que oferece pouca possibilidade para a ludicidade como forma de expressão infantil, esse projeto educativo coloca a criança na posição subalterna de aluno, o que pode promover as primeiras experiências de resistência infantil ao poder docente. Assim, encontramos na escola manifestações da cultura dos alunos, expressas em termos de comportamentos de oposição à cultura escolar.

Assim, as expressões da cultura de oposição desses alunos aparecem ligadas às formas específicas de controle hegemônico na escola e chamam atenção, provavelmente de maneira não consciente, para as suas necessidades mais significativas, que são conquistas da infância. Sant'Ana $(2002,2010)$ também identificou nessa instituição pré-escolar de São João del-Rei, Minas Gerais, a oposição entre brincadeira e trabalho como motor de conflito na interação entre professor e alunos. Na organização das atividades da rotina, os momentos de brincadeira e os momentos de trabalho eram bem distintos e demarcados. Além disso, o jogo e a brincadeira na rotina escolar ofereciam algumas experiências prazerosas para o aluno, para que ele suportasse o regime disciplinar imposto ao seu corpo. Ao mesmo tempo, certas atividades são disfarçadas de brincadeiras, de modo a impedir a resistência da criança à tarefa.

Geralmente, a resistência infantil ao poder dos educadores apresenta-se predominantemente de duas maneiras: a) uma resistência 
"visível", nomeada como "ativa" pelo fato de apresentar confrontação aberta da autoridade escolar, que é desafiada pela afirmação da "potência", por parte da criança ou seu grupo; b) uma resistência "invisível", que pode ser nomeada de "passiva", pois o sujeito, ou seu grupo, não desafia ou revida a autoridade, mas se ajusta à situação por meio de uma ação paralela não claramente contestatória, de modo a conseguir algum prazer em meio às interdições impostas pela autoridade (de falar, brincar, portar objetos de forte significado simbólico para o sujeito e seu grupo de pertença ou referência). A autora percebeu manifestações abertas, ou seja, uma forma de resistência ativa, de oposição das crianças às tarefas mais propriamente pedagógicas, cujo alvo principal era a alfabetização. Em duas das turmas observadas, as professoras aumentaram demais a quantidade de exercícios mimeografados oferecidos às crianças - para três lições antes do recreio (antes davam uma a duas lições) -, que, no entanto, não atendiam ao ritmo imposto. Quando o sinal do recreio tocava, a professora se via obrigada a recolher as tarefas incompletas, para retomá-las em outra ocasião. Os conflitos entre crianças e professora ocorriam frequentemente, com recusa daquelas a ouvir as instruções de preenchimento das folhas mimeografadas: crianças conversavam, não prestavam atenção ao que a professora dizia e, uma vez ou outra, até repetiam para os colegas de mesa, em tom de zombaria, as instruções dadas. As crianças diziam querer estar com os seus pares e brincar entre si. A professora ignorava a demanda e continuava a tarefa; por vezes, dizia que elas logo poderiam sair para brincar. Aparentando descrença em relação ao que ouvia, parcela expressiva das crianças impunha uma forte interação social paralela àquela promovida pela professora.

A autora concluiu que o controle do tempo e dos movimentos e a interdição à sociabilidade infantil, definidos pela professora, provocam, uma vez ou outra, resistências infantis, desafiando soluções a meio termo entre as demandas da professora e as das crianças. Diante disso, podemos concluir que os comportamentos de oposição infantil exercem, não necessariamente de modo consciente, certo controle sobre a intensidade e o ritmo do trabalho (PERRENOUD, 1988), o que, muitas vezes, leva a alguns ajustes entre a professora e as crianças na condução das atividades, no que diz respeito, principalmente, ao ritmo estabelecido para cada situação.

Sant'Ana (2010) identificou que, já no primeiro ano da préescola, alguns meninos perceberam que poderiam assumir o papel do transgressor da ordem ao ocupar o lugar do "bagunceiro". 
Um grupo de meninos demonstrava fazer, dentro da sala de aula e no recreio, um esforço enorme para chamar atenção de seus colegas por meio de comportamentos de oposição às educadoras. Durante o recreio, era comum um ou outro menino ser obrigado a permanecer sentado ao lado da professora como penalidade por alguma forma de transgressão. Então, desenvolveu-se um grupo de "bagunceiros" que, por vezes, corria em grande velocidade para provocar punições pelas professoras e, assim, ser consagrado perante a comunidade discente como o grupo dos meninos mais valentes da escola. Inclusive, um ou outro perguntava (com um sorriso de expectativa de punição) se ficaria de castigo naquele dia. No segundo ano da pré-escola, o grupo dos "bagunceiros" sofreu uma deserção significativa - a pesquisadora perguntou pelas crianças e os educadores responderam que os pais pediram sua transferência de escola. Alguns dos remanescentes, porém, continuaram a ocupar o lugar de "bagunceiro" até o último ano da "escola primária". A resistência mais visível ao poder das professoras ocorre entre os meninos, por meio de expressões predominantemente masculinas, provavelmente ligadas ao seu universo sociocultural de pertença ou de referência. As meninas, mais frequentemente, traziam para a interação social elementos de uma cultura infantil de gênero mais próxima ao mundo das professoras (a troca de objetos de adorno, maquiagem, conversas sobre amizade e inimizade, passeios, festas, etc.).

Diversos estudos apontam diferenças de gênero nas formas com que crianças e adolescentes lidam com a escola e suas exigências. Porém, alguns se atêm às resistências e oposições infantojuvenis, sem preocupação imediata com as supostas ligações disso com as posições de classe ou gênero, como é o caso do trabalho de Perrenoud (1988) que contribuiu muito para o desenvolvimento da reflexão aqui apresentada.

Na próxima seção do texto, traremos elementos teóricos sobre a cultura dos alunos nos quatro ou cinco anos do Ensino Fundamental, período aqui denominado "escola primária", para, em seguida, esboçarmos um quadro teórico sobre a cultura do aluno focado na discussão da pré-escola aos primeiros anos do Ensino Fundamental.

\section{AS ESTRATÉGIAS NA CULTURA DOS ALUNOS NA "ESCOLA PRIMÁRIA"}

À medida que a discussão sobre os comportamentos dos alunos desloca-se para os níveis de ensino posteriores à pré-escola, os movimentos individuais e coletivos diante das tarefas escolares e das interações sociais que envolvem tais tarefas recebem novas 
denominações. Em diferentes quadros teóricos o aluno é concebido como um estrategista, que, em maior ou menor grau, procura definir as situações, no aqui e agora das interações sociais, segundo seus interesses mediatos ou imediatos. Abordagens interacionistas radicais tendem a valorizar mais as definições de situação no lidar cotidiano com as atividades que compõem o "oficio do aluno", de maneira que as estratégias dos autores repousam muito mais no que o jogo interacional permite conforme os contextos escolares, do que as supostas referências socioculturais de pertença ou de referência localizadas na família, na comunidade ou na rua.

As abordagens interacionistas consideram como objeto de análise o trabalho de ajustamento, de negociação e de compromisso entre os atores e a situação no contexto interacional. Conforme Woods (1980), os interacionistas nomeiam como "comportamento estratégico" a habilidade de mudar conforme as circunstâncias. Entram em jogo, o tempo todo, lógicas de ação cujo sentido é construído pelos atores em meio às negociações ali em curso. Tais negociações envolvem concessões, ganho e perda, e podem ser abertas ou tacitamente estabelecidas. "Negociação" é um conceito chave e base para a ação estratégica, a qual pode permitir ganhos simbólicos ou materiais para indivíduos e grupos.

Para Woods (1980), há a "negociação aberta" quando as partes se movem de algum modo para conhecer umas às outras, e as suas demandas por vontade própria; e a "negociação fechada" quando "cada parte, independentemente, procura maximizar sua própria realidade, em oposição e conflito em relação ao outro, e cada um [faz] concessões a contragosto, e somente se forçado" (WOODS, 1980, p. 14). Assim, comumente os modelos interacionistas de pesquisa levam em conta uma dimensão observável concernente ao professor, ao aluno e às suas relações para entender as lógicas das ações dos atores.

Para Woods $(1980,1998)$, a questão crucial é que essas estratégias podem aparecer ocasionalmente, mas tornam-se parte do estoque de experiências, que serve como um recurso para lidar com contingências que possam surgir futuramente. Uma vez compartilhadas e disseminadas por um grande número de alunos, passam a fazer parte de uma cultura de alunos e podem ser manifestadas nos planos individual e coletivo. Desse modo, a cultura dos alunos detém um acúmulo de conhecimentos e práticas - que podem permanecer latentes ou se manifestar conforme a situação.

Foge às finalidades deste artigo discorrer sobre a origem das estratégias dos atores (Perrenoud, 1988). Como escolhemos conduzir 
a discussão por meio da contribuição desse autor, aqui o relevo incide sobre as estratégias engendradas pelos alunos frente às tarefas escolares, não são problematizados, os níveis de intencionalidade dos atores e as razões da escolha de uma ou outra estratégia, o que poderia ser objeto de publicações posteriores

Sant'Ana (2007) registrou, na primeira série do Ensino Fundamental, diversas expressões de oposição ao poder docente, sobretudo na sala de uma professora cuja relação com as crianças se mostrava baseada em uma extrema racionalidade. Assim,

o buscar arduamente o controle delas por meio de admoestações, formas veladas de humilhação, ameaças constantes de punição, em tom de voz educado e polido, não impede que formas de resistência ao controle irrompam no cenário. As formas de resistência visualizadas foram: a) um modelo "instituído" de transgressão, próprio à cultura escolar: exibição pública de transgressão de normas disciplinares; b) o "marca-passo" (a busca do controle do ritmo das atividades, fazendo mais lentamente as tarefas, cujas consequências mais comuns são as punições, o recreio é usado para completar a tarefa $[\ldots]$; c) o alheamento em relação a certas atividades do "oficio do aluno" (não prestar atenção em certas atividades conduzidas pela professora, embora a atenção seja despertada por acontecimentos simples, como o brinquedo que cai do bolso de uma criança); d) sair do ambiente (solicitação constante de ida ao banheiro)[...] (SANT'ANA, 2007, p. 58).

Elementos de uma cultura de alunos modulada pelas pertenças de gênero aparecem na análise. Nos interstícios das interações entre a professora e os alunos, marcadas pelo anonimato e pela frieza relacional,

grupos de meninas, frequentemente constituídos desde a pré-escola, apresentam uma rede de interações que a professora parece não capturar: cochicham, compartilham objetos trazidos de casa, falam de amizade, paquera e namoro, construindo um subuniverso cultural próprio (elementos de uma cultura intrageracional) que quebra, pelo menos parcialmente, com o anonimato que a relação professor-aluno acaba por apresentar. Meninos, mais frequentemente, parecem manifestar a potência de agir, frente a um padrão de interação que ameaça submetê-los a um papel social de "aluno", baseado na obediência e no servilismo, por meio do confronto com as normas de condutas instituídas pela professora (SANT'ANA, 2007, p. 58).

A tarefa provoca resistência, mas o mesmo acontece com a relação social estabelecida para que a tarefa ocorra. Na pré-escola e na "escola primária" o comportamento da professora pode diminuir ou aumentar a resistência do aluno à tarefa.

Perrenoud (1988) argumenta que os alunos têm uma relação estratégica com as regras da organização didática que deveriam 
governar as suas atividades, pois, longe de fazer constantemente tudo o que os professores lhes pedem, eles tentam negociar ou burlar regras e instruções. Em um de seus estudos, que será aqui apresentado, o autor mostra que os alunos, mesmo na escola elementar, desenvolvem estratégias para proteger o seu mundo contra as exigências adultas no tocante a aspectos como interesse, liberdade e tranquilidade.

Ao refletir sobre as estratégias individuais e coletivas dos atores diante das instituições, Perrenoud ajuda-nos a compreender o comportamento dos alunos. Duas possibilidades de ação estratégicas são visualizadas pelo autor, ou seja, entre atuar sobre as regras ou jogar com elas,

a escolha dos atores depende de multiplos paramêtros, entre os quais a natureza do ganho: é possível obter certas coisas utilizando de maneira sábia o sistema existente, mais, de outra maneira, passando por sua transformação explícita. Importa igualmente as representações que os atores têm do sistema: os prisioneiros de um modelo formalista ou jurídico da organização, eles terão tendência a não ver que é possível jogar com as regras ou a não se permitir isso; os mais cínicos ou mais clarividentes usam seu conhecimento intuitivo do funcionamento das organizações para burlar as regras e não se opor abertamente (PERRENOUD, 1988, p. 2-3).

Os alunos do início do processo de escolarização começam a aprendizagem do jogo escolar com os mecanismos e as regras específicos que nascem do interior do jogo. Perrenoud afirma que o mais comum é que os alunos, em geral, sejam

praticamente condenados a estratégias essencialmente defensivas, que consistem em jogar com as regras, a contorná-las, a escapar delas ou a negociar a aplicação caso por caso. Essas estratégias também devem permanecer clandestinas. Nenhuma organização reconhece prontamente a seus membros o direito de jogar com as regras, para interpretar, para tirar proveito de suas zonas sombrias e contradições. Mais no interior de determinados sistemas se considera informalmente que é uma "boa guerra" ou mesmo que ela contribui, em certa medida, ao bom funcionamento do conjunto [...] (1988, p. 3).

Porém, o jogar com as regras escolares por parte dos alunos não é visto como algo que contribui para melhorar a vida dentro da escola. Aceita-se uma sociabilidade infantojuvenil bem comportada, ajustada à rotina escolar. Perrenoud (1988, p. 4) nos lembra que muitos adultos negam ao aluno o "direito de realizar estratégias para defender seu ponto de vista, para manter uma fachada para esconder suas 'asas' para manter um discurso duplo, para enganar ou mentir para proteger seus interesses ou de solidariedade [...]". 


\section{PEDAGOGIAS TRADICIONAIS VERSUS PEDAGOGIAS NOVAS}

Perrenoud apresenta uma tipologia diferenciadora dos modelos de práticas pedagógicas dominantes na "escola primária". A tipologia formulada por Perrenoud (1988) distingue as pedagogias tradicionais, expressas por meio de tarefas tradicionais, das pedagogias novas, expressas mediante tarefas novas. Estas nascem de um conjunto diversificado de teorias cujo parentesco nem sempre existiu originalmente. Perrenoud (1988, p. 106) refere-se às fontes inspiradoras dessas novas pedagogias nos seguintes termos:

[...] essa expressão deliberadamente vaga designa as práticas que se inspiram de perto ou de longe em "pais fundadores" tão diversos como Freinet, Decroly, Ferrière, Montessori, Dewey, Bovet, Claparède ou mais recentemente Dottrens, Neil, Piaget, Steiner, Rogers, Hameline, Ferry, Oury ou outros das pedagogias "modernas", "ativas", "não diretivas", cooperativas ou institucionais. Tratandose de uma história das ideias pedagógicas o amálgama seria indefensável: cada um desses autores tem um pensamento original, há entre eles muitas diferenças, por vezes contradições. Uma sociologia dos movimentos constituídos que se proclamam da escola moderna, nova ou ativa, deveria igualmente levar em conta a especificidade de cada um.

\section{DIDÁTICA TRADICIONAL VERSUS DIDÁTICAS NOVAS (ATIVAS)}

Perrenoud constrói uma abordagem diferenciadora das pedagogias em termos da organização do trabalho dos alunos, a partir da distinção entre a didática tradicional e as didáticas novas (ativas) e identifica as modalidades de resistência às tarefas escolares empreendidas pelos alunos em cada uma dessas modalidades de organização didática.

No caso da didática tradicional, no dia a dia do manejo do trabalho educativo, o professor desenvolve as atividades progressivamente, dentro de um quadro relativamente previsível de sucessão dos conteúdos do programa. O professor trilha um caminho relativamente seguro oferecido pelos exercícios pré-fixados, pelo programa estabelecido e pela organização das atividades em etapas. Por outro lado, as didáticas novas (ativas) exigem o manejo de um conjunto de ações combinadas de modo flexível, dentro de um quadro relativamente móvel de progressão dos conteúdos do programa, de modo a permitir a autonomia e as vivências dos alunos.

$\mathrm{Na}$ didática tradicional, o professor trabalha cada conteúdo dirigindo-se à classe para explicar noções, expondo novos conhecimentos e definindo a terminologia correspondente a cada assunto. Ele mostra objetos ou ilustrações e fornece exemplos. 
Por questionamento, ele procura se assegurar de que os alunos compreendem a explicação e são capazes de memorizar o conteúdo mais importante. Os alunos não permanecem passivos todo o tempo, pois devem repetir fatos, regras e teoremas. Portanto, para Perrenoud (1998) a didática tradicional poderia ser resumida pelas atividades de lições, exercícios e controle do conteúdo adquirido, de modo que

uma vez que as noções sejam introduzidas, os alunos são convidados a fazer exercícios, por vezes oralmente, muito frequentemente por escrito, a partir de instruções dadas, anotados na lousa ou impressos nos manuais ou caderno de exercícios. Lições e exercícios se combinam em proporção variável para cobrir as noções constitutivas de um capítulo do plano de estudos. Quando o mestre julga que um número suficiente de alunos compreendeu ou aprendeu, ele lhe interroga oralmente ou lhe administra uma prova escrita; essa avaliação, também o fato de que ela é formalmente comunicada aos alunos ou aos seus pais, permite ao mestre "virar" a página e abordar um novo capítulo do programa (PERRENOUD, 1988, p. 5).

Segundo Perrenoud (1998), as novas didáticas apresentam-se como alternativas às didáticas tradicionais, em oposição às formas clássicas de ensino e atividades escolares. Os pais fundadores dos movimentos de renovação das ideias pedagógicas são, principalmente, Freinet, Bovet, Dewey, Ferrière, Claparède, Decroly e Piaget. De forma geral, essas ideias podem ser caracterizadas como orientadas por uma concepção de aprendizagem muito mais centrada no aluno do que no professor, o que implica

\footnotetext{
na construção progressiva dos conhecimentos e do saber-fazer não apenas através de uma actividade própria mas igualmente através das interações sociais, tanto entre alunos como entre o professor e os alunos; desejar juntar as disciplinas, privilegiar competências funcionais e globais por oposição a aquisições conceptuais e aos saberes fragmentados; desejar abrir a escola à vida, assentar as aprendizagens escolares em experiências do quotidiano, das "vivências" dos alunos; respeitar a diversidade das personalidades e das culturas; valorizar a autonomia da criança, do self-government do grupo-turma, pelo menos dentro de certos limites; atribuir uma maior valorização à motivação intrínseca, ao prazer, ao desejo de descobrir e de fazer, por oposição às práticas tradicionais da recompensa e do castigo; atribuir uma maior importância aos aspectos cooperativos do trabalho escolar e ao funcionamento do grupo-turma, por oposição às tarefas estritamente individuais e à competição entre alunos; atribuir uma maior importância à educação e ao desenvolvimento da pessoa, por oposição a uma centração exclusiva sobre os saberes ou o saber-fazer (PERRENOUD, 1988, p. 11-12).
}

No trabalho de Perrenoud (1998), a tarefa e a sua definição distinguem as duas didáticas e as formas de oposição discente que cada uma permite (voltaremos a isso adiante). Quando falamos de "tarefas tradicionais" versus "tarefas novas" (ativas), estamos referindo-nos a 
um conjunto de práticas dos educadores que se apresentam na forma de um ordenamento típico das tarefas, resumidas no quadro abaixo:

\section{QUADRO 1}

Tarefas Tradicionais versus Tarefas Novas (Ativas)

\begin{tabular}{|l|l|}
\hline \multicolumn{2}{|c|}{ Tipos de tarefas na didática tradicional e nas didáticas novas } \\
\hline \multicolumn{1}{|c|}{ Tarefas na pedagogia tradicional } & \multicolumn{1}{|c|}{ Tarefas nas pedagogias novas } \\
\hline Idênticas para todos; & $\begin{array}{l}\text { Diferenciada em função da diversidade } \\
\text { de interesses das crianças; }\end{array}$ \\
\hline $\begin{array}{l}\text { Fechadas: os passos requeridos para a sua } \\
\text { concretização já estão definidos a priori; }\end{array}$ & $\begin{array}{l}\text { Abertas: elas não apelam a uma solução } \\
\text { única, vão se definindo progressivamente em } \\
\text { função do processo pedagógico; }\end{array}$ \\
\hline $\begin{array}{l}\text { Fragmentadas: alternância rápida de tarefas } \\
\text { curtas; }\end{array}$ & $\begin{array}{l}\text { Globais: elas nascem de problemas que } \\
\text { requerem uma integração de tarefas } \\
\text { diferenciadas; }\end{array}$ \\
\hline $\begin{array}{l}\text { A mesma tarefa para todos ao mesmo tempo; } \\
\text { Escolhidas em função de sua facilidade } \\
\text { e possibilidadades de correção. }\end{array}$ & $\begin{array}{l}\text { Os alunos geralmente realizam tarefas } \\
\text { conforme suas necessidades e preferências; }\end{array}$ \\
\hline $\begin{array}{l}\text { Relativamente fáceis: exigem poucos } \\
\text { recursos para a sua compreensão; } \\
\text { Ênfasenáveis; na escrita; }\end{array}$ & $\begin{array}{l}\text { Escolhidas pela sua utilidade prática ou pelo } \\
\text { interesse do aluno. }\end{array}$ \\
\hline é útil;
\end{tabular}

Fonte: elaborado pelo autor deste artigo. 


\section{AS OPOSIÇ̃̃ES E RESISTÊNCIAS ȦS TAREFAS}

As formas que as tarefas assumem sempre abrem brechas para estratégias de oposição e de resistência discentes. Os dispositivos de poder e controle sobre a criança, próprios de cada pedagogia, não deixam de provocar nos alunos práticas, não necessariamente conscientes, de redefinição de tarefas indesejadas. $\mathrm{Na}$ "escola primária", na maioria das vezes, são estratégias sutis para proteção contra atividades indesejadas, de modo que o aluno, em grupo ou individualmente, evita confrontos diretos com os professores.

\section{A RELAÇÃO ESTRATÉGICA COM O TRABALHO ESCOLAR NA DIDÁTICA TRADICIONAL}

Diante das formas clássicas de prática escolar docente, a criança pode desenvolver estratégias de eficácia inegável para controlar, ao seu próprio modo, a oferta e o ritmo do trabalho, embora o campo de possibilidades de ação aberto por cada didática coloque limites aos atores. O autor elenca cinco estratégias clássicas de defesa engendradas pelos alunos (conforme Perrenoud, 1988). São elas:

a) Beber o cálice até a última gota: o estudante obedece à lógica do sistema sem revolta sem discutir ou fazer perguntas. Ele investe pouco de si, com a satisfação de que seu resultado, mesmo que não seja inatacável, pelo menos provoca pouca suspeita de má vontade.

b) Rápido! Rápido! Rápido! Ou como se desembaraçar: trata-se de fazer o mais rapidamente possível as tarefas para fazer qualquer outra coisa. Para tal pode ser necessário resumir apressadamente desenvolvendo pouco o raciocínio ou copiar de um vizinho, para desfrutar de uma breve pausa até que o professor dê um novo trabalho.

c) Acelere lentamente: sem recusar abertamente a tarefa, encontrar formas de ganhar tempo, mostrar-se ocupado sem fazer esforço, fingir interesse pelos exercícios e problemas propostos, interromper para apontar o lápis, pedir e aguardar uma explicação são estratégias comumente utilizadas.

d) 'Eu não entendo nada!'”: Mostrar-se incompetente, alegando incapacidade de entender as instruções e/ou de encontrar um caminho para a solução, a fim de justificar longos períodos de inatividade, especialmente se o professor se recusa a responder perguntas ou se encontra ocupado com outros alunos.

e) Contestação aberta: a estratégia mais perigosa, pois se nega abertamente a utilidade do trabalho dado, até mesmo se recusa 
explicitamente a fazê-lo, alegando falta de interesse, falta de desejo, fadiga ou mau humor. Poucos estudantes têm condições de adotar regularmente essa estratégia sem enfrentar sérios problemas disciplinares. Aqueles que a usam com frequência geralmente não têm muita coisa a perder. Uma forma de contestação aberta mais sutil ocorre quando os alunos dizem que o trabalho é difícil demais e que, portanto, é inútil começar ou quando dizem que já fizeram demais esse tipo de tarefa antes e que ela não acrescenta nada ao que eles já sabem.

\section{A RELAC̣ÃO ESTRATÉGICA COM O TRABALHO ESCOLAR NAS NOVAS DIDÁTICAS}

Conforme Perrenoud (1988), as estratégias próprias à didática tradicional permanecem parcialmente válidas no interior das novas didáticas, sendo ainda possível lançar mão das cinco estratégias acima descritas; porém, em outros aspectos, as coisas se complicam para os alunos, pois

[...] o conformismo é menos fácil, porque as normas são menos claras e o aluno não pode simplesmente seguir os trilhos; quanto à contestação, ela implica o aluno não somente em uma relação de forças, mas também em um trabalho intelectual construtivo: se o aluno não está de acordo com a tarefa, ele deve propor alguma coisa mais interessante, havendo um risco de uma demanda por maior esforço! Assim torna-se mais difícil se livrar rapidamente de uma tarefa para se ocupar de outra coisa, já que como a tarefa não é definida com anterioridade ela pode se complicar na medida em que o professor está sempre preste a impulsionar o aluno a atingir uma etapa com novas pistas, a estabelecer um novo desafio, inventar um novo problema. Trabalhar muito rápido [para se livrar rapidamente da tarefa] se torna menos interessante pois frequentemente é uma condenação a mais trabalho. (PERRENOUD, 1988, p. 14)

Porém, uma estratégia ainda possível consiste em o aluno fazer o professor crer que ele não tem nenhuma ideia acerca do que fazer diante de uma demanda mais global e, assim, mostrar lentidão e pouco entusiasmo. Perrenoud identifica que, frente às tarefas abertas e mais criativas, a má vontade se traveste facilmente de impotência ou incompetência. Além dessas estratégias (PERRENOUD, 1988), algumas específicas das novas didáticas são resumidas abaixo:

a) Monopolizar as tarefas seguras: alunos que detestam tarefas abertas, reflexivas, escolhem, entre as atividades possíveis, sempre aquelas que se aproximam mais do trabalho escolar tradicional, como copiar um texto, classificar e ordenar fichas e documentos, procurar palavras numa lista, etc., ou seja, as tarefas mais simples e individuais que fazem parte de atividades complexas e coletivas. Assim, embora aparentem participar 
de uma pedagogia nova, na verdade executam atividades relativamente estereotipadas, reproduzindo condutas bem conformistas.

b) Organizar o trabalho dos outros: alguns alunos que apresentam apenas um interesse limitado e se tornam porta-vozes do grupo organizam a discussão, estimulam o engajamento dos outros, mas, de fato, não se engajam nas atividades estritamente pedagógicas;

c) Desaparecer nos interstícios: certos alunos, em todas as classes, tentam "sair de fininho", escapar a certas tarefas, o que é mais difícil quando todo mundo tem de fazer o mesmo exercício. Quando as tarefas se diversificam, exigindo iniciativas e propostas, torna-se possível nada propor! Certos alunos evitam mostrar sua falta de interesse, fingindo fazer um enorme esforço mental. Eles desenvolvem formas de escapar ao controle do professor.

d) O ativismo desordenado: certos alunos estão o tempo todo muito ocupados, hiperativos. Porém, um olhar atento mostra que eles estão engajados em tarefas que não apresentam nenhuma relação com aquelas definidas pelo mestre. "Certos alunos verificam avidamente no dicionário palavras que não se tem necessidade, fazem cálculos sem relação com o problema, medem, cortam, desenham, não importa o quê, sob pretexto de contribuir à tarefa comum. Essa agitação não parece muito fonte de aprendizagem, mas produz a ilusão" (PERRENOUD, 1988, p. 15).

e) Cavalgar sozinho: certos alunos, geralmente os melhores, destacam-se do conjunto da turma e, individualmente ou em dupla, distanciam-se das tarefas comuns em direção a atividades mais próximas aos seus objetivos e medidas. Se

o professor tenta diferenciar seu ensino, uma didática nova pode, dentro de certos limites, estabelecer para os alunos mais fracos um regime de trabalho parcialmente independente das atividades do grupo classe, o que pode levá-los a recorrer menos às estratégias defensivas, as quais condenam o trabalho escolar tradicional. (PERRENOUD, 1988, p. 15-16)

Perrenoud (1988) e Woods (1980) dizem que a orientação dos alunos diante das atividades escolares e das relações sociais com os professores é dominada pelo jogar com as regras presentes no contexto escolar. Para o primeiro autor, as formas de jogar o jogo escolar estão no centro da dinâmica escolar e orientam o exercício do "ofício de aluno". A condição de aprendente leva os alunos a procurarem "negociar", de maneira mais ou menos explícita, posicionamentos diante dos ritmos, normas e valores que ali circulam. 
Até aqui procuramos mostrar formas de jogar o jogo, indicando tendências diversas de um grupo de alunos em relação a outro, de uma didática a outra. Uma vez apresentado esse pequeno inventário de resistência discente, notamos que o principal elemento diferenciador das formas de oposição e resistência das crianças da "escola primária" em relação aos adolescentes dos níveis de ensino posterior é o uso mais difundido da contestação aberta por parte destes no jogo escolar, o que parece estar associado a problemas disciplinares. Nesse caso, torna-se difícil discernir a resistência à tarefa da resistência ao poder do professor como autoridade, bem como as possíveis relações entre as duas dimensões da experiência escolar.

\section{CULTURA DOS ALUNOS: UMA CULTURA NA ESCOLA}

Para Waller (1932) e Woods (1980), existem dinâmicas próprias dos alunos e dinâmicas próprias dos professores, cujas diferenças são produtoras da inevitabilidade do conflito na ação educativa. Podemos perceber que, com o transcorrer dos anos escolares, os alunos passam a deter um vasto conhecimento do jogo interativo que ocorre na sala de aula. $\mathrm{O}$ jogo relacional traz a possibilidade de os alunos, em maior ou menor grau, colocarem em xeque e testarem, de diferentes formas, os repertórios de ação de seus professores e, assim, poderem definir os tons da relação. Vimos que os códigos da interação e as estratégias usadas são tributários da cultura que os alunos, como categoria submetida, constituem num constante fazer-se histórico, que delineia alguns cenários em que a interação deverá acontecer (BUENO; SANT'ANA, 2011).

Poderíamos pensar que existem duas culturas que os alunos tecem na escola diante da cultura escolar: uma cultura de negociação entre professores e adolescentes, em que estes aceitam todas as exigências daqueles em nome do sucesso escolar, e outra cultura, de oposição e resistência, cujo ponto mais alto seria a negação juvenil de toda e qualquer negociação com a autoridade adulta docente. Haveria, então, uma cultura de total adesão aos ideais escolares, em que a cultura juvenil se cola à cultura escolar, e outra que suspeita dela ou a nega.

Aqui, o que se defende é que se trata de uma mesma cultura, pois os diversos movimentos dos alunos tem como ponto em comum a necessidade de lidar com um lugar de subalternidade geracional, com uma dada configuração das relações sociais que é dada pela forma escolar. Não é somente uma relação de subordinação geracional, mas é também uma forma bem específica de constituição dessa relação 
estabelecida historicamente, no interior da forma escolar. Como afirma Weller (1932), coexistem diferentes culturas na escola, mas ele prefere ater-se a duas, quais sejam, a de um grupo dado como dominante (o professor como representante da autoridade adulta) e a dos alunos, em estatuto de minoridade e de subalternidade geracional. Essas duas culturas assumem diferentes formas de expressão e os sujeitos que as vivem podem fazer aproximações e distanciamentos críticos entre elas, mas elas nunca se misturam completamente.

No interior da escola podem existir gangues, "panelinhas", "bobos", "palhaços", ou seja, um conjunto de tipos sociais que apresentam manifestações ora a favor da autoridade, ora contra a autoridade no interior de um mesmo jogo. As posições dos jogadores e as jogadas possíveis não são infinitas, mas, ao mesmo tempo, não se resumem a uma mera repetição de formas já dadas por antecipação. Isso depende também de para onde o contexto sociocultural "empurra" a escola e os jogadores em ação no seu interior. Os atores escolhem como se comportar a partir dos recursos materiais e simbólicos aos quais têm acesso, bem como a partir do repertório cultural constituído para definir e lidar com as situações dadas no contexto.

No contexto da educação compulsória, o apelo a uma autoridade não negociada não garante o controle do jogo e a promoção de comportamentos disciplinados. Woods (1980) argumenta que, embora seja geralmente reconhecido que o professor tenha mais poder do que o aluno no sentido de criação de demandas e definição da cena e esteja imbuído de autoridade, em um contexto de "educação obrigatória a extensão em que um professor pode influenciar o aluno de acordo com suas intenções em qualquer situação é altamente problemática" (WOODS, 1980, p. 14). O contexto sociocultural "empurra" a escola para a gestão de situações que exigem mais do corpo docente, pois este tem de lidar com sujeitos recalcitrantes em relação às tarefas escolares, às regras e às relações sociais subjacentes a essas situações.

Por sua vez, as ações coletivas que crianças e adolescentes desenvolvem na escola tornam-se parte da vida escolar - desejada ou indesejada - e da produção de uma série de sociabilidades de pares. Por isso, crianças e adolescentes, mesmo que de uma forma diferente da dos adultos professores, são coconstrutores da escola e da sociedade, inclusive na forma de um movimento subversivo e não consciente que modifica a forma escolar.

$\mathrm{Na}$ contemporaneidade, a infância e a adolescência permanecem, em grande parte, determinadas pelo recorte institucional escolar. Grande parte do tempo da vida infantojuvenil é vivida na escola, lugar onde 
coexistem os dois estatutos, o do aluno e o do sujeito, pois a condição de aluno também é afetada pelo estatuto civil do sujeito que ele ocupa.

A adolescência possui maior autonomia do que a infância e menor do que a juventude, e isso tende a produzir condições sociais diferenciadas no interior da sala de aula e na escola como um todo. Os dados aqui apresentados reforçam a ideia de que a condição infantil favorece mais o estatuto de subalternidade social do aluno do que a condição adolescente e constitui formas de oposição e resistência escolar mais brandas se tomamos como referência a confrontação constante, aberta e direta atribuída a alunos adolescentes.

Uma apreensão interacionista das mudanças no estatuto do aluno é apresentada por Woods (1980), que faz uso da expressão "carreira" para discorrer sobre o percurso escolar do aluno como marcado por "uma série de passos ou estágios. A progressão é por meio de um número de status que mudam em pontos significativos determinados em primeira instância pelas instituições" (WOODS, 1980, p. 17). Para Woods (1980), a passagem da "escola primária" para a seguinte é um desses pontos significativos, a entrada no Ensino Médio é outro e assim por diante. Para o autor, as passagens podem ser desejáveis ou indesejáveis, voluntárias ou involuntárias, e cada ponto de passagem envolve formas estratégicas de lidar com elas por parte dos alunos, as quais se ligam a elementos como status, poder e aspirações.

A discussão sobre as estratégias discentes tende a fixar os alunos em dois polos estratégicos. Os "bons alunos" geralmente são os estrategistas que seguem uma orientação próxima à teoria dos jogos nos domínios social e institucional. Esses alunos apresentamse como indivíduos que se orientam pela situação, mas fazem escolhas racionais em função de seus projetos e de conhecimentos que detêm sobre o mercado de trabalho, as carreiras acadêmicas, etc., movendo-se por uma lógica de integração ao sistema escolar e ao sistema social. Por outro lado, os "maus alunos" são tidos como orientados, sobretudo, por estratégias de ganho imediato, cuja racionalidade é circunscrita ao aqui e agora da interação face a face. Assim, coexistiriam duas lógicas orientando a cultura dos alunos? Isto é, uma de mobilidade social, de melhoria ou manutenção da posição de classe, e outra, mais imediatista, reativa, defensiva e de resistência às tarefas e ao poder discente, que favoreceriam a perpetuação da estrutura de desigualdades sociais existente?

Quando refletimos acerca da cultura do aluno na pré-escola e no Ensino Fundamental, essas duas concepções de sujeito estrategista parecem não dar conta das lógicas de ação dessas crianças como 
sujeitos sociais. Embora tenham comportamentos estratégicos, não podemos dizer que elas sejam estrategistas o tempo todo. O mais comum é que as crianças oscilem, centrando-se ora nas tarefas, ora nas pessoas e interações sociais, ora nas exigências do "ofício do aluno", ora, ainda, nas suas necessidades infantis.

Portanto, a cultura dos alunos da pré-escola e dos primeiros anos do ensino fundamental é uma cultura engendrada dentro da escola e se concretiza na intersecção entre a cultura infantil e a cultura escolar, com diferentes níveis de proximidade e distanciamento. Nela se imiscuem referências socioculturais diversas, tais como culturas familiares, comunitárias, culturas de gênero e etnias, etc., contribuindo para modulá-las em maior ou menor grau. Ou seja, essa cultura pode receber influências de culturas originárias e fincadas em outros grupos de pertença ou de referência para as crianças.

\section{REFERÊNCIAS}

BERNSTEIN, B. A estruturação do discurso pedagógico: classe, códigos e controle. Petrópolis: Vozes, 1996.

BUENO, F. A.; SANT'ANA, R. B. A experiência geracional na fala de alunos de escola pública: a questão da autoridade docente. R. bras. Est. pedag., Brasília, v. 92, n. 231, p. 316340, mai./ago. 2011. Disponível em: <http://rbep.inep.gov.br/index.php/RBEP/article/ viewFile/1805/1606>. Acesso em: $1^{\circ}$ jun. 2011.

DUBET, F; MARTUCCELLI, D. À l'école: sociologie de l'expérience scolaire. Paris: Seuil, 1986.

MOLLO-BOUVIER, S. Transformação dos modos de socialização das crianças: uma abordagem sociológica. Educação e Sociedade, Campinas, n. 91, p. 391-403, mai./agosto, 2005. Disponível em <http://www.scielo.br/pdf/es/v26n91/a05v2691.pdf>. Acesso em: 5 jul. 2007.

MONTANDON, C. Sociologia da infância: balanço dos trabalhos em língua inglesa. Cadernos de Pesquisa, n. 112, p. 33-60, mar./2001. Disponível em < http://www.scielo.br/ pdf/cp/n112/16100.pdf>. Acesso em 04/07/2007.

PERRENOUD, P. Nouvelles didactiques et stratégies des élèves face au travail scolaire. In: PERRENOUD, P ; MONTANDON, C. (dir.) Qui maîtrise l'école? Politiques d'institutions et pratiques des acteurs, Lausanne, Réalités sociales, 1988, p. 175-195 Disponível em: <http:// www.unige.ch/fapse/SSE/teachers/perrenoud/>, p. 1-16. Acesso em: 4 mai. 2013.

SACRISTÁN, J. G. O aluno como invenção. Porto Alegre: Artmed, 2005.

SANT'ANA, R. B. Experiências formativas em pré-escola: sob a perspectiva da psicologia social de G. H. Mead. 2002, 214f. Tese (Doutoramento em Psicologia Social) - Pontifícia Universidade Católica, São Paulo, 2002.

SANT'ANA, R. B. de. Rotina Escolar na Primeira Série do ensino fundamental. In: PEREIRA, L. H. P; OLIVEIRA, W. C. (Orgs.). Práticas Educativas: discursos e produção de saberes. 1 ed. Rio de Janeiro: E-Papers, 2007, p. 31-62. 
SANT'ANA, R. B. de. Rotinas e Atividades Educativas em Pré-escola. Inter-ação, Goiânia, UFG., v. 1, p. 175-188, janeiro/junho/2010. Disponível em: <http://www.revistas.ufg.br/ index.php/interacao/article/download/13139/8534\%E2\%80\%8E \%20Em $\% 20$ cache $\% 20$ Semelhante>. Acesso em: 10 jul. 2010.

SARMENTO, M. J. Gerações e alteridade: interrogações a partir da sociologia da infância. Educ. Soc., Campinas, v. 26, n. 91, p. 361-378, mai./ago. 2005. Disponível em: <http://www. scielo.br/pdf/es/v26n91/a03v2691.pdf>. Acesso em 4 abr. 2007.

SARMENTO, M. J. Lógicas de Ação nas Escolas. Lisboa: Instituto de Inovação Educacional, 2000. SIROTA, Régine. Emergência de uma sociologia da infância: evolução do objeto e do olhar. Cadernos de Pesquisa, São Paulo, Fundação Carlos Chagas, n. 112, mar./2001, p. 7-31. Disponível em: <http://www.scielo.br/scielo.php?pid=S010015742001000100001\&script= sci_abstract\&tlng=pt $>$. Acesso em : 4 jul. 2007.

VASQUEZ-BRONFMAN, A.; MARTINEZ, I. La socialisation a l'école: approche ethnographique. Paris: PUF, 1996.

VINCENT, G.; LAHIRE, B.; THIN, D. Sobre a história e a teoria da forma escolar. Educação em Revista, Belo Horizonte, n. 33, p. 7-47, jun. 2001.

WALLER, W. The sociology of teaching. New York: John Wiley and Sons, 1932.

WOODS, P. The development of pupil strategies. In: WOODS, P. (Ed.) Pupil strategies: explorations in the sociology of the school. London: Croom Helm, 1980, p. 11-28.

\section{NOTAS}

${ }^{1}$ A expressão "escola primária" equivale hoje aos cinco primeiros anos do Ensino Fundamental. Embora em desuso nos textos oficiais, é aqui usada propositalmente a fim de provocar imagens e representações que apelam à continuidade com o passado. $\mathrm{O}$ pressuposto subjacente é de que apesar das inúmeras reformas político-pedagógicas ocorridas nesse nível/ciclo de ensino, não houve ruptura com a forma escolar constituída historicamente, o que é possível visualizar em elementos como o regime curricular, pedagógico e disciplinar, o estatuto social de minoridade da criança, a cultura docente e assim por diante.

${ }^{2}$ Do ponto de vista da Psicologia e da Sociologia, um grupo de pares é considerado um agrupamento composto de pessoas de estatuto social igual ou similar, que compartilham interesses e pontos de vista sociais comuns e oferecem referências socioculturais para a formação da identidade pessoal e social. Geralmente o conceito se refere mais especificamente aos grupos infantis e juvenis como agrupamentos de idade que permitem aos seus participantes viverem experiências sociais sem supervisão adulta, e, ao mesmo tempo, constituirem códigos relacionais e valorativos diferentes daqueles apresentadas pelos adultos, sobretudo pais e professores.

Recebido: 08/05/2014

Aprovado: 02/12/2014 
Contato:

Universidade Federal de São João Del-Rei

Departamento das Psicologias

Praça Dom Helvecio, 74 Fábricas

São João del Rei, |MG|Brasil

CEP 36.300-000 
